\title{
Prevention of Contrast-induced Nephropathy by Cordyceps among Patients undergoing Percutaneous Coronary Procedures using Intravenous Contrast
}

\author{
Marvyn Allen G. Chan, ${ }^{1}$ Kenneth Wilson O. Lim ${ }^{1}$ and Elizabeth Salazar-Montemayor ${ }^{2}$ \\ ${ }^{1}$ Department of Medicine, Philippine General Hospital, University of the Philippines Manila \\ ${ }^{2}$ Section of Nephrology, Department of Medicine, College of Medicine and Philippine General Hospital, University of the Philippines Manila
}

\begin{abstract}
Objectives. This study aimed to determine the efficacy and safety of Cordyceps in preventing occurrence of contrastinduced nephropathy (CIN) among patients undergoing CA / PCI using IV contrast compared to standard therapy.

Methods. We searched Medline, Embase, Cochrane database, and Google Scholars for RCTs involving the use of Cordyceps in contrast-induced nephropathy. We used the search keywords "Cordyceps" and "contrast-induced nephropathy" with the Boolean operator "AND" and filtering search results to include only randomized controlled trials and clinical trials. Three trials were found which satisfied all the inclusion criteria and none of the exclusion criteria.
\end{abstract}

Results. No patient developed clinical renal failure, adverse reactions, or side effects with the Cordyceps arm. CIN occurred in 26 out of 285 patients. The incidence of CIN was less in the Cordyceps group compared to the standard therapy group $(\mathrm{p}<0.05, \mathrm{Cl} 0.20,1.00)$.

Conclusion. Cordyceps shows a trend towards prevention of CIN and a decrease in biomarkers for acute kidney injury. More studies with larger populations need to be performed to further clarify its preventive effects.

Key Words: Acute Kidney Injury, CIN, Contrast-induced Nephropathy, Cordyceps, INterluekin-18, IL-18, KIM-1, Meta-analysis, NGAL

\section{INTRODUCTION}

Contrast-induced nephropathy (CIN) or contrastinduced acute kidney injury (CI-AKI) is defined by the Kidney Disease: Improving Global Outcomes (KDIGO) as a rise in serum creatinine of $>0.5 \mathrm{mg} / \mathrm{dL}(>44 \mathrm{umol} / \mathrm{L})$, or serum creatinine rise of $>25 \%$, within 48 hours after administration of intravascular contrast media. ${ }^{1} \mathrm{~A}$ study by Nash et al back in 2002, described that contrast-induced nephropathy is the $3^{\text {rd }}$ most common cause of hospital acquired renal insufficiency reaching up to $11 \%$ of cases. ${ }^{2}$ The prevalence of CIN in the global population however is only $0.6-2.3 \%$. This incidence is increased in a certain subset of patients. Particularly, in patients with acute myocardial

Corresponding author: Marvyn Allen G. Chan, MD Department of Medicine Philippine General Hospital University of the Philippines Manila Taft Avenue, Ermita, Manila 1000 Philippines Telephone: +63933 8603070 Email: marvyn_chan@yahoo.com infarction undergoing percutaneous coronary intervention, the incidence can go as high as $19 \% .^{3}$ A case series in Mayo Clinic and in William Beaumont Hospital reported a CIN incidence of $3.3 \%$ and $14.5 \%$, respectively among patients with cardiovascular disease. ${ }^{4,5}$ Among these, $0.7 \%$ and $0.3 \%$, respectively underwent dialysis. In a prospective cohort study 
by Balemans, the incidence of CIN was $2.4 \%$ among those with an eGFR of less than $60 \mathrm{~mL} / \mathrm{min} / 1.73 \mathrm{~m}^{2}$ who received intravenous iodinated contrast material. ${ }^{6}$

Development of CIN is associated with a variety of adverse outcomes. In a study by Giacoppo et al., they analyzed pooled patients with acute myocardial infarction undergoing percutaneous coronary intervention from the Harmonizing Outcomes with Revascularization and Stents in Acute Myocardial Infarction (HORIZONS-AMI) and Acute Catheterization and Urgent Intervention Triage Strategy (ACUITY) multicenter randomized trials. ${ }^{7}$ They observed that patients who developed CIN showed increased risk of short and long-term ischemic and hemorrhagic events as well as increase in mortality rates in 30 days and in 1 year. These events included re-infarction, stent thrombosis, and major bleeding. However, it should also be noted that patients who develop CIN tend to be older and with more comorbidities. These particular subsets of patients are again restressed in the study by Balemans, who demonstrated that comorbidity such as obesity, heart failure, and repeated contrast media use have increased risk. ${ }^{6}$

Because of significant morbidity associated with CIN, numerous novel biomarkers have been proposed to detect acute kidney injury even before there is a rise in serum creatinine or a fall in urine output. These novel biomarkers include Interleukin-18 (IL-18), Neutrophil GelatinaseAssociated Lipocalin (NGAL), N-acetyl-glucosaminidase (NAG), Kidney Injury Molecule 1(Kim-1), L-type Fatty Acid Binding Protein (L-AFBP), and Cystatin C (Cys-C).

Interleukin-18 is a proinflammatory cytokine released in the proximal tubules of ischemic acute kidney injury. It peaks in 24 hours and remains elevated up to 48 hours. ${ }^{8}$ It is more sensitive than serum creatinine in detecting CI-AKI by as much as 24-48 hours prior to a rise in serum creatinine. ${ }^{9}$ Mawad et al, however, observed that Il-18 can be elevated as early as 3 hours. ${ }^{10}$

Cys- $\mathrm{C}$ is a protein present in all nucleated cells and is produced at a constant rate. It is also freely filtered like creatinine, however unlike creatinine it is not secreted. Therefore, changes in Cys- $\mathrm{C}$ can reflect changes in GFR. Cys- $\mathrm{C}$ changes can be detected as early as 24 hours. A rise of Cys-C of $<10 \%$ within 24 hours will exclude CI-AKI, while a rise of $>10 \%$ within 24 hours will be an independent predictor of major adverse events. ${ }^{11}$

NGAL is a protein upregulated in proximal tubules following ischemic injury. It peaks at 2 hours and declines in 6 hours. ${ }^{12}$ It is also the most extensively studied novel biomarkers for acute kidney injury. Kafkas et al., demonstrated that NGAL predicted patients undergoing invasive cardiac procedures that may need further observation. ${ }^{13}$ Tong et al. demonstrated in a meta-analysis that NGAL can predict CIN within 2-6 hours in adults with a sensitivity of $80 \%$, specificity of $83 \%$, diagnostic odds ratio of 20.57 and an AUROC of $0.87 .{ }^{14} \mathrm{~A}$ study by Khatami et al demonstrated that at a NGAL urinary concentration of $22.5 \mathrm{ng} / \mathrm{mL}$, sensitivity is $71.4 \%$ and specificity at $57.9 \%$ for AKI in patients with normal serum creatinine. ${ }^{15}$

KIM-1 is a membrane glycoprotein that is shed by proximal tubules in ischemic acute kidney injury. ${ }^{16} \mathrm{KIM}-1$ can be elevated as early as 24 hours after angiographic procedures before the rise of serum creatinine, which usually takes place after 48 hours. ${ }^{17}$ The study by Xie et al also demonstrated that high levels of KIM-1 has a positive correlation for very severe renal injury, predicting that for every $1 \mathrm{ng} / \mathrm{mg}$ increase in urinary KIM-1, renal function deterioration after AKI increases by $6.4 \%{ }^{18}$

NAG is a marker of damage to proximal tubules. NAG is usually present in small amounts in the urine since it is not freely filtered due to its large molecular weight. However, with proximal tubule injury and disruption, urinary NAG levels rises. Urinary NAG levels will start to rise by $50 \%$ in 24 hours and remain high even after 6 days in subjects undergoing contrast procedures. ${ }^{19}$ Chew et al. demonstrated that high urinary NAG portrays a poorer prognosis. ${ }^{20}$

Identifying risk factors for the development of CIN is invaluable in the prevention of CIN. They can be categorized as patient or contrast agent related risk factors. ${ }^{21}$ Patient risk factors include: GFR less than $60 \mathrm{~mL} / \mathrm{min} / 1.73 \mathrm{~m}^{2}$, dehydration, congestive heart failure, gout, age over 70 , concurrent administration of nephrotoxic drug, diabetes, hypertension, low hematocrit, hypotension, and low ejection fraction $(<40 \%)$. Contrast agent related risk factors include: high doses of contrast agent, $(>100 \mathrm{~mL})$, high osmolality, and high viscosity.

Hydration is the widely accepted method of decreasing the risk of developing CIN. ${ }^{21}$ In a study by Jurado-Roman, patients undergoing primary percutaneous coronary intervention (PPCI) were randomized to receive isotonic saline hydration with a rate of $1 \mathrm{ml} / \mathrm{kg} / \mathrm{hr}$ at the beginning of the procedure until 24 hours after. ${ }^{22}$ Those who received intravenous saline hydration during primary percutaneous coronary intervention had a $48 \%$ reduced risk of developing CIN.

Other recommendations in preventing CIN include (1) limiting contrast media volume, (2) using pre-heated IOCM, (3) stopping nephrotoxic drugs $48 \mathrm{hrs}$ before contrast media exposure. ${ }^{23}$ Short term statin therapy has also been shown to decrease risk for CIN. A study by Han et al randomized 2,998 diabetic patients with rosuvastatin $10 \mathrm{mg}$ a day, 2 days prior and 3 days after exposure to contrast medium. They noted a significantly lower incidence of CIN $(2.3 \%$ vs $3.9 \%$; $p=0.01)$ among those treated with statin vs standard of care. ${ }^{24}$

Cordyceps is a fungus which is parasitic to insects and arthropods. It is usually grown in altitudes as high as 35004000 meters above sea level. They have long been used in traditional Chinese medicine and is used mainly for problems relating to the kidneys and the lungs. Numerous in-vitro studies have already been made demonstrating its antitumor, anti-inflammatory, anti-viral, anti-angiogenic, and anti-oxidant properties. Several bioactive compounds have 
already been characterized, particularly cordycepin, adenosine derivatives, ophiocordin, L-tryptophan, polysaccharides, modified nucleosides, and cyclosporine-like metabolites. ${ }^{25,26}$

Cordycepin, is a 3'-deoxyadenosine nucleoside analogue from Cordyceps. In vitro studies showed anti-tumor effects against liver cancer cells HepG2 and human cancer cells. ${ }^{27,28}$ The mechanism of which was thought to be through the activation of caspases through either cytochrome $\mathrm{C}$ release from the mitochondria or Fas-induced apoptotic pathways. Immunomodulatory activity via interleukin 10 pathway have also been demonstrated..$^{29}$

Cordyceps polysaccharides have been shown by a study by Ji et al to demonstrate synergistic effects with chemotherapeutic regimens showing improved response and can be a viable adjuvant chemotherapeutic regimen. ${ }^{25}$ Its antioxidant activity has been demonstrated in vitro to inhibit inflammation and reactive oxygen species production in human mesangial cells which may provide a therapeutic target for glomerulonephritis. ${ }^{30}$

Its anti-inflammatory and antioxidant potential is also being studied for patients with diabetes mellitus. An in vitro study by Liu et al, demonstrated its ability to protect pancreatic beta-cells by reducing the expression of pro-apoptotic reflecting endoplasmic reticulum stress. The application of Cordyceps on chronic complications of diabetes such as diabetic kidney disease and diabetic cardiomyopathy have also been studied in vitro and shows promise. $^{31}$

Besides the benefits of its anti-inflammatory and antioxidant property in diabetes, in vitro studies have also been shown that it exerts a beneficial effect on other acute organ system injuries that may be explained by reactive oxygen species and inflammation. ${ }^{32-34}$ Moreover, its free radical scavenging property has been used to modulate the cytotoxic effects on normal cells of chemotherapeutic drugs such as cisplatin and doxorubicin..$^{35,26}$

Cordyceps have also been widely used for treatment of kidney diseases. In Chinese traditional medicine, it is widely known for its renoprotective effects. A meta-analysis by Luo et al for the use of Cordyceps together with ARB/ ACEi for treatment of diabetic kidney disease suggests a beneficial effect, however because of the heterogeneity of included trials in the study, a definitive conclusion cannot be maintained. ${ }^{36} \mathrm{An} \mathrm{RCT}$ trial by Zhang et al, demonstrated the immunomodulatory effects in chronic allograft nephropathy patients, either improving the disease or stabilizing the disease. ${ }^{37}$ Because of its antioxidant and anti-inflammatory properties, an in vitro study by Liu et al, showed its effect in the prevention of liver and heart injury in patients with chronic kidney disease. ${ }^{38}$

Because of these in vitro properties and its traditional use in Chinese medicine for kidney diseases, it is thought that it could have protective effects on the kidney. In light of this, we are investigating the potential role of Cordyceps extracts in protecting the kidney against contrast- induced nephropathy, particularly in patients undergoing percutaneous coronary procedures.

\section{OBJECTIVE}

This study aimed to determine the efficacy and safety of Cordyceps in preventing occurrence of CIN among patients undergoing CA / PCI using IV contrast compared to standard therapy.

\section{Specific objectives}

1. Measure the difference in change of eGFR among those taking Cordyceps vs standard therapy

2. Measure the difference in change markers for acute kidney injury, specifically NGAL, Interleukin-18 and KIM-1 among those taking Cordyceps vs standard therapy

\section{METHODS}

\section{Search methods and data gathering}

We searched Medline, Embase, Cochrane database, and Google Scholars for RCTs involving the use of Cordyceps in contrast-induced nephropathy. We used the search keywords "cordyceps" and "contrast-induced nephropathy" with the Boolean operator "AND" and filtering search results to include only randomized controlled trials and clinical trials. Inclusion of additional search terms such as "Percutaneous Coronary Intervention" or "Coronary Angiogram" will result to 0 hits; therefore, we only resorted to use the search terms "cordyceps" and "contrast-induced nephropathy", to which Medline returned 3 articles, Cochrane database returned 5 relevant articles, Embase returned 0, and Google Scholars returned 39 results.

We also sought consult from nephrologists locally who are into the field of researching the application of these kinds of extracts in renal disease. Unfortunately, not enough information was still available locally as of this time in the application of Cordyceps for contrast-induced nephropathy.

\section{Data collection and screening}

Articles obtained from Medline, Cochrane database, and Google Scholar were first screened for duplicates. After screening out the duplicates, only three articles were left. The three articles then were assessed using our inclusion criteria specifically: 1) randomized controlled trial or clinical trials, 2) use of Cordyceps, 3) use of intravenous contrast in cardiac procedures, 4) evaluation for contrast-induced nephropathy using traditional markers such as eGFR and serum creatinine and novel markers for acute kidney injury such as NGAL, KIM-1, NAG, cystatin-C and Interleukin 18; and exclusion criteria: 1) patients on end-stage renal disease, defined as a calculated eGFR using the CKD-epi method of $<15 \mathrm{~mL} / \mathrm{min}$, 2) age 18 and below, 3) hypersensitivity to contrast media, 4) severe end organ damage (severe heart failure, end-stage 


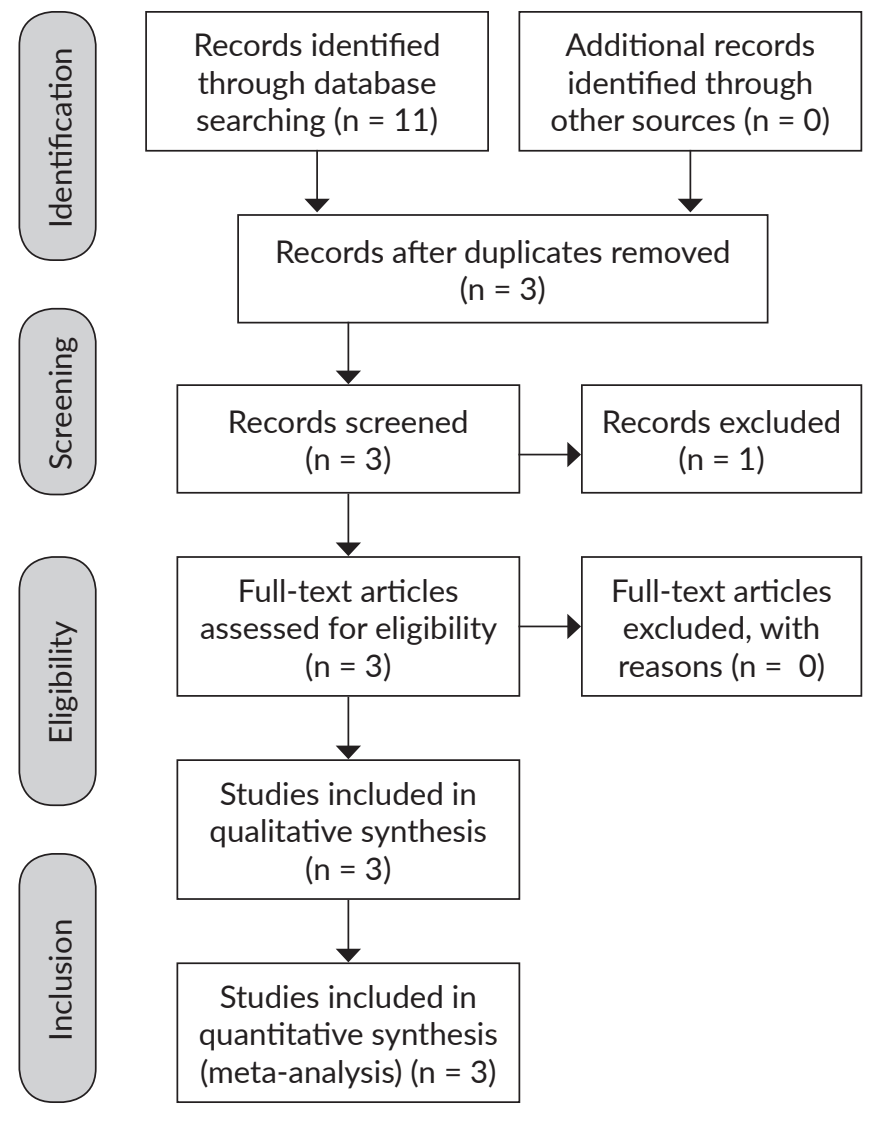

Figure 1. Prisma flow sheet.

renal disease, liver cirrhosis, acute hepatic failure), and 5) hypersensitivity to Cordyceps.

All three articles passed the eligibility screening and subsequently underwent quantitative assessment.

Data from the articles were extracted using a data extraction sheet shown in Appendix A. Study characteristics from each of the article was obtained as shown in Appendix B.

The data obtained were analyzed and primary outcomes were based on the incidence of CIN described as a $25 \%$ increase in creatinine from the baseline or an absolute value of 0.5 $\mathrm{mg} / \mathrm{dL}$ (44 micromol/L) within 48-72 hours of intravenous contrast use. Secondary outcomes were analyzed based on the change in eGFR, serum creatinine, and novel markers for acute kidney injury (Ngal, Interleukin-18 and Kim-1). The articles were assessed for heterogeneity. Correction for heterogeneity were attempted by using sub-group analysis or using random effect model of analysis.

\section{Description of studies}

Three trials fulfilled our inclusion criteria and none of our exclusion criteria. The trials were conducted at Tianjin Nankai Hospital in 2013, 2014, and 2015. All 3 trials had similar population, age groups, inclusion and exclusion criteria, dosage of Cordyceps, and outcome measurements as described in Table 1.

\section{Risk of bias}

All three trials used a random numbers table as method for randomization. All participants included in the trials were included and completed follow-up and they were all assessed in their original group. There was no mention of allocation concealment or blinding of either participant or personnel. There was also no mention of blinding of outcome assessment, however, laboratory values are not affected by assessors' assessment making it unlikely to be a source of bias. Figure 2 and Figure 3 summarize the risk of bias.

\section{Safety}

In all 3 trials, no patient developed clinical renal failure. No side effects were noted in both Cordyceps and standard treatment group. No adverse reactions were noted during the procedure in all trials.

\section{Primary outcome}

In total, CIN occurred in 26 out of 285 patients (Table 2). As shown in Figure 4, the incidence of CIN was significantly less in the Cordyceps group compared to the standard therapy group ( $p<0.05$, CI $0.20,1.00)$. There was no heterogeneity between the studies with an $\mathrm{I} 2$ of $0 \%$.

\section{Secondary outcome}

For our secondary outcomes, the increase in KIM-1, NGAL, and IL-18 were significantly lesser in the cordyceps group compared to the standard therapy group $(\mathrm{P}<0.05)$ as depicted in Figure 5, Figure 6 and Figure 7, respectively.

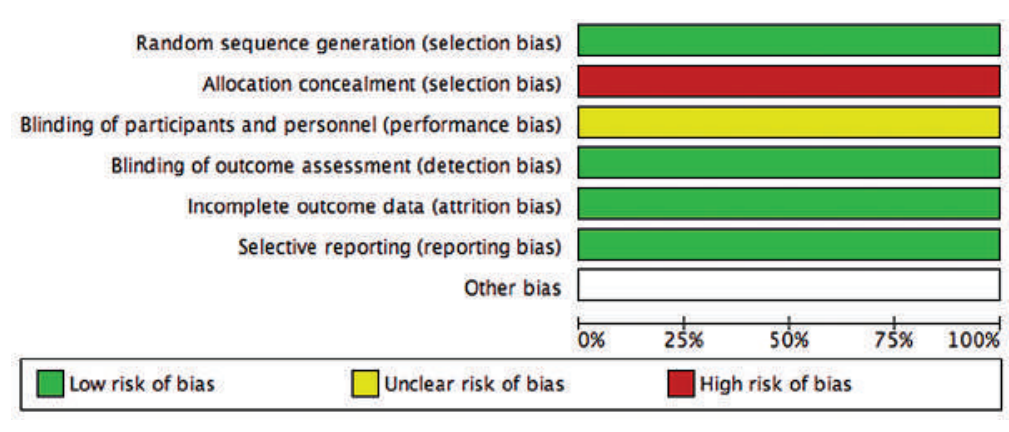

Figure 2. Risk of bias.

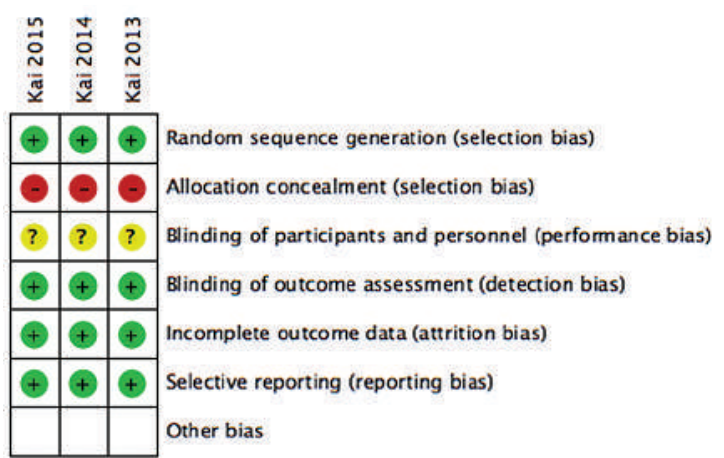

Figure 3. Summary of risk of bias. 
Table 1. Description of studies

\begin{tabular}{|c|c|c|c|}
\hline Trial & $\begin{array}{l}\text { Role of Dongchongxiacao } \\
\text { (Cordyceps) in prevention } \\
\text { of contrast-induced } \\
\text { nephropathy in patients } \\
\text { with stable angina pectoris }\end{array}$ & $\begin{array}{l}\text { Efficacy of short-term Cordyceps sinensis } \\
\text { for prevention of contrast-induced } \\
\text { nephropathy in patients with acute coronary } \\
\text { syndrome undergoing elective percutaneous } \\
\text { coronary intervention }\end{array}$ & $\begin{array}{l}\text { Effect of Dongchongxiacao (Cordyceps) } \\
\text { therapy on contrast-induced } \\
\text { nephropathy in patients with type } \\
2 \text { diabetes and renal insufficiency } \\
\text { undergoing coronary angiography }\end{array}$ \\
\hline Author & $\begin{array}{l}\text { Kai Zhao, Yongjian Li, } \\
\text { Hong Zhang }\end{array}$ & Kai Zhao*, Yu Lin*, Yong-Jian Li, Sheng Gao & Zhao Kai, Li Yongjian, Gao Sheng, Lin Yu \\
\hline Year & 2013 & 2014 & 2015 \\
\hline Journal & $\begin{array}{l}\text { Journal of Traditional } \\
\text { Chinese Medicine }\end{array}$ & Int J Clin Exp Med & Journal of Traditional Chinese Medicine \\
\hline Type & $\mathrm{RCT}$ & RCT & RCT \\
\hline Inclusion & $\begin{array}{l}>18 \text { years and }<80 \text { years of } \\
\text { age; SAP had to conform to } \\
\text { guidelines set by the relevant } \\
\text { organization in China in } 2007\end{array}$ & $\begin{array}{l}\text { - } \geq 18 \text { years and } \leq 75 \text { years of age } \\
\text { - ACS: diagnosed according to the criteria } \\
\text { issued by AHA, which includes acute } \\
\text { myocardial infarction and unstable } \\
\text { angina pectoris. unstable angina pectoris } \\
\text { and myocardial infarction attacked more } \\
\text { than } 7 \text { days }\end{array}$ & $\begin{array}{l}\text { - } \quad>18 \text { and }<80 \text { years of age } \\
\text { - } \text { with type } 2 \text { diabetes } \\
\text { - } \text { eGFR was } \leq 60 \mathrm{~mL} / \mathrm{min} / 1.73 \mathrm{~m}^{2}\end{array}$ \\
\hline Exclusion & $\begin{array}{l}\text { Hyperpyrexic or allergic to } \\
\text { iodine or who had one of the } \\
\text { following tumours; severe } \\
\text { heart failure; severe kidney } \\
\text { failure; severe liver failure; } \\
\text { disorders of the immune } \\
\text { system; blood disease }\end{array}$ & $\begin{array}{l}\text { Cardiac shock or state supported by device, } \\
\text { such as intra-aortic balloon pump (IABP). } \\
\text { hyperpyrexic or allergic to iodine or } \\
\text { who had one of the following: severe kidney } \\
\text { failure, severe congestive heart failure, } \\
\text { severe liver failure, disorders of the immune } \\
\text { system, tumors, and blood diseases. }\end{array}$ & $\begin{array}{l}\text { Hyperpyrexic or allergic to iodine or } \\
\text { who had one of the following tumours; } \\
\text { severe heart failure; severe kidney } \\
\text { failure; severe liver failure; disorders of } \\
\text { the immune system; blood disease }\end{array}$ \\
\hline Intervention & $\begin{array}{l}\text { 3g corbin cap, TID3 days } \\
\text { before angiography } \\
\text { All patients received } \\
\text { physiological }(0.9 \%) \text { saline } \\
\text { (i.v.) at } 1 \mathrm{~mL} / \mathrm{kg} \text { per hour -for } \\
6 \text { h before, and } 12 \mathrm{~h} \text { after, } \\
\text { contrast exposure. }\end{array}$ & $\begin{array}{l}\text { Standard } 2 \mathrm{~g} \text { corbin cap, TID3 days before } \\
\text { angiography } \\
\text { Intensive } 3 \mathrm{~g} \text { corbin cap, TID3 days before } \\
\text { angiography } \\
\text { All patients were hydrated with intravenous } \\
\text { half-isotonic saline at a rate of } 1 \mathrm{mg} / \mathrm{kg} \text { per } \\
\text { hour for } 12 \text { hours before and } 12 \text { hours after } \\
\text { coronary catheterization. }\end{array}$ & $\begin{array}{l}\text { Standard } 2 \mathrm{~g} \text { corbin cap, TID } 3 \text { days } \\
\text { before angiography } \\
\text { Intensive } 3 \mathrm{~g} \text { corbin cap, TID3 days } \\
\text { before angiography } \\
\text { All patients were given intravenous } \\
\text { isotonic saline }(0.9 \%) \text { at a rate of } \\
\text { approximately } 1 \mathrm{~mL} / \mathrm{kg} \text { per hour } \\
\text { for } 6 \mathrm{~h} \text { before, and } 12 \mathrm{~h} \text { after, } \\
\text { contrast exposure. }\end{array}$ \\
\hline Control & $\begin{array}{l}\text { All patients received } \\
\text { physiological } \\
(0.9 \%) \text { saline (i.v.) at } 1 \mathrm{~mL} / \mathrm{kg} \\
\text { per hour for } 6 \text { h before,and } \\
12 \text { h after, contrast exposure. } \\
\\
\text { Subjects in the basic } \\
\text { treatment group received } \\
\text { hydration, } \\
\text { anti-platelet agents, statins, } \\
\text { and anticoagulant therapy. }\end{array}$ & $\begin{array}{l}\text { All patients were hydrated with intravenous } \\
\text { half-isotonic saline at a rate of } 1 \mathrm{mg} / \mathrm{kg} \text { per } \\
\text { hour for } 12 \text { hours before and } 12 \text { hours after } \\
\text { coronary catheterization. } \\
\text { Subjects in the basic treatment group } \\
\text { received hydration, } \\
\text { anti-platelet agents, statins, and } \\
\text { anticoagulant therapy. } \\
\text { Interventional procedure was performed } \\
\text { according to standard clinical practice using } \\
\text { the femoral or radial approach }\end{array}$ & $\begin{array}{l}\text { Standard Therapy } \\
\text { All patients were given intravenous } \\
\text { isotonic saline } \\
(0.9 \%) \text { at a rate of approximately } \\
1 \mathrm{~mL} / \mathrm{kg} \text { per hour for } 6 \mathrm{~h} \text { before, and } \\
12 \mathrm{~h} \text { after, contrast exposure. } \\
\text { (Aspirin, clopidogrel, rosuvastatin, } \\
\text { metoprolol, benazepril, } \\
\text { fondaparinux, furosemide) }\end{array}$ \\
\hline $\begin{array}{l}\text { Primary } \\
\text { outcome measures }\end{array}$ & Incidence of CIN & Incidence of CIN & Incidence of $\mathrm{CIN}$ \\
\hline $\begin{array}{l}\text { Secondary } \\
\text { outcome measures }\end{array}$ & $\begin{array}{l}25 \% \text { or greater reduction } \\
\text { in eGFR; changes in urine } \\
\text { KIM-1, NGAL, IL-18 }\end{array}$ & $\begin{array}{l}25 \% \text { or greater reduction in eGFR; changes } \\
\text { in urine KIM-1, NGAL, IL-18 }\end{array}$ & $\begin{array}{l}25 \% \text { or greater reduction in eGFR; } \\
\text { changes in urine KIM-1, NGAL, IL-18 }\end{array}$ \\
\hline
\end{tabular}

Table 2. Results

\begin{tabular}{|c|c|c|c|c|c|c|}
\hline \multirow[t]{2}{*}{ Trial } & \multicolumn{2}{|c|}{$\begin{array}{l}\text { Role of Dongchongxiacao } \\
\text { (Cordyceps) in prevention of CIN } \\
\text { in patients with stable angina } \\
\text { pectoris }\end{array}$} & \multicolumn{2}{|c|}{$\begin{array}{l}\text { Efficacy of short-term cordyceps } \\
\text { sinensis for prevention of CIN } \\
\text { in patients with acute coronary } \\
\text { syndrome undergoing elective } \\
\text { percutaneous coronary intervention }\end{array}$} & \multicolumn{2}{|c|}{$\begin{array}{l}\text { Effect of Dongchongxiacao } \\
\text { (Cordyceps) therapy on CIN with } \\
\text { T2DM and renal insufficiency } \\
\text { undergoing coronary angiography }\end{array}$} \\
\hline & Intervention (52) & Control (51) & Intervention (50 int) & Control (51) & Intervention (40 int) & Control (41) \\
\hline Incidence of CIN & $3(5.77)$ (Int) & $6(11.76)$ & $3(6.0)(\operatorname{lnt})$ & $6(11.76)$ & 2 (5.00) (Int) & $6(14.63)$ \\
\hline Change in urine KIM-1 & $2.21 \pm 0.29(\operatorname{Int})$ & $5.81 \pm 0.32$ & $2.77 \pm 0.33(\ln t)$ & $5.63 \pm 0.27$ & $2.76 \pm 0.32(\ln t)$ & $5.62 \pm 0.28$ \\
\hline Change in urine NGAL & $39.65 \pm 8.42$ (Int) & $67.36 \pm 11.85$ & $41.66 \pm 8.42$ (Int) & $66.53 \pm 10.74$ & $41.65 \pm 8.41$ (Int) & $66.52 \pm 10.73$ \\
\hline Change in urine IL-18 & $48.10 \pm 3.52$ (Int) & $61.79 \pm 4.85$ & $46.78 \pm 4.33$ (Int) & $62.14 \pm 3.53$ & $46.79 \pm 4.32$ (Int) & $62.13 \pm 3.52$ \\
\hline
\end{tabular}




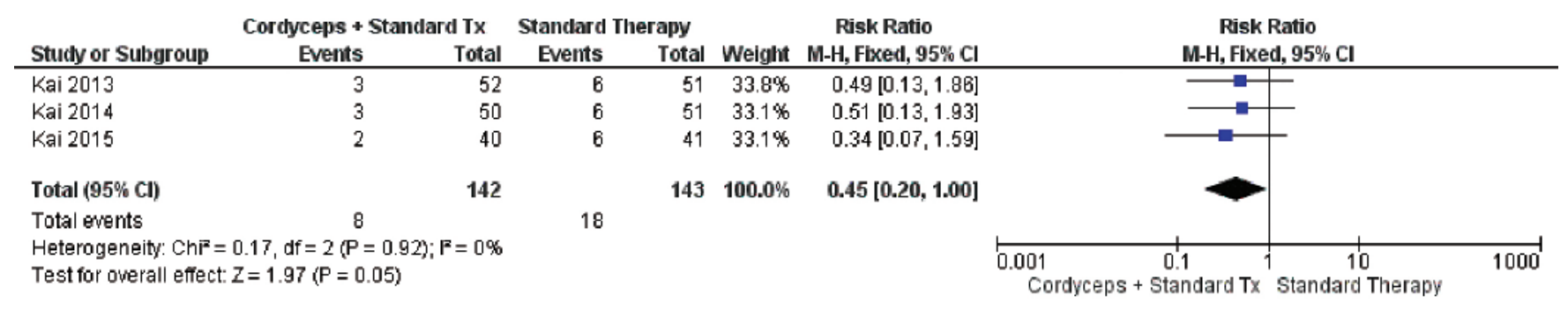

Figure 4. Forest plot of incidence of CIN between treatment (Cordyceps) and control (standard therapy) group.

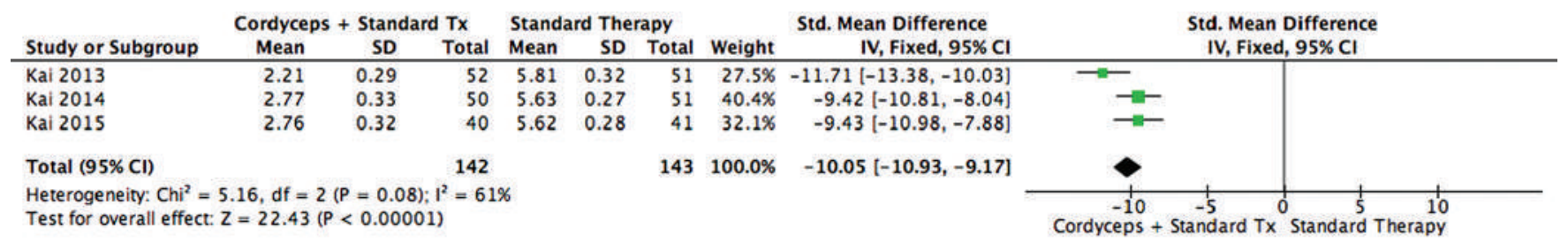

Figure 5. Forest plot showing standard mean difference in urinary KIM-1 concentration between treatment (Cordyceps) and control (standard therapy) group.

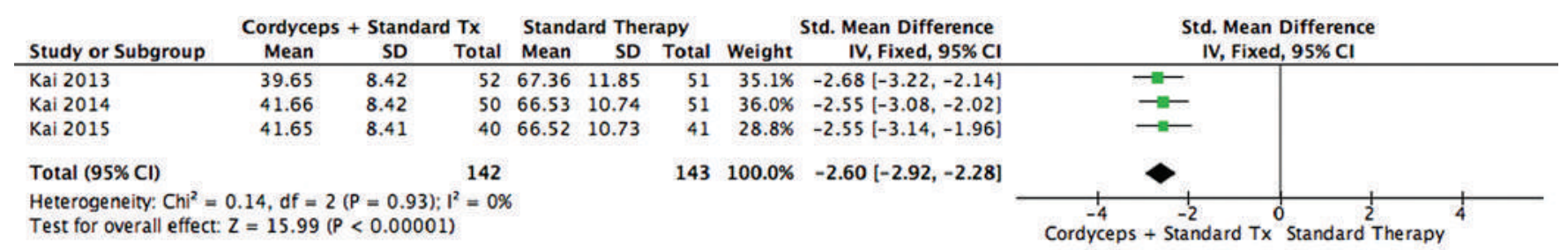

Figure 6. Forest plot showing standard mean difference in NGAL concentration between treatment (Cordyceps) and control (standard therapy) group.

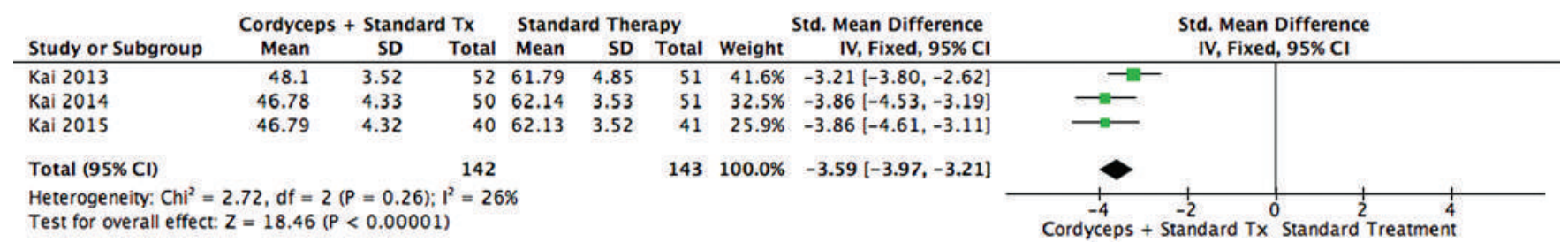

Figure 7. Forest plot showing standard mean difference in urinary IL-18 concentration between treatment (Cordyceps) and control (standard therapy) group.

\section{DISCUSSION}

$\mathrm{CIN}$ is defined as a rise in serum creatinine of $>0.5 \mathrm{mg} / \mathrm{dL}$ ( $>44 \mathrm{umol} / \mathrm{L}$ ), or serum creatinine rise of $>25 \%$, within 48 hours after administration of intravascular contrast media. It is the $3 \mathrm{rd}$ most common hospital acquired renal insufficiency and its global prevalence is $0.6-2.3 \%$. Those who do develop CIN have an increased risk in short and long-term ischemic and hemorrhagic events as well as mortality. Novel biomarkers such as IL-18, NGAL, NAG, KIM-1, L-AFBP, and cystatin- $\mathrm{C}$ have been identified which could identify acute kidney injury much earlier than serum creatinine, potentially allowing earlier detection and intervention of developing kidney disease.

Hydration is the widely accepted method in decreasing the risk for development of CIN. Other recommendations would include limiting contrast media volume, using preheated IOCM, withholding nephrotoxic drugs $48 \mathrm{hrs}$ prior to contrast media exposure. Statin therapy has also been proved to lessen the risk of development of CIN. Nevertheless, considering the morbidities associated with developing CIN and its long term effects, any additional therapy that could further reduce this risk is a welcome addition.

Cordycep has long been used in traditional Chinese medicine for treatment of heart and lung. In vitro studies have demonstrated antitumor, anti-inflammatory, antiviral, antiangiogenic and antioxidant properties. It has also been widely used for treatment of kidney diseases, primarily known for its renoprotective effects.

We analyzed 3 randomized controlled trials which studied the effect of Cordyceps in decreasing the risk for developing CIN among patients undergoing percutaneous 
coronary intervention. No participant developed clinical renal failure, had any adverse reactions or side effects or needing hemodialysis to both the Cordyceps and standard therapy group. The incidence of CIN was less in the Cordyceps group compared to the standard therapy group. However, the change was not significant with a p-value of 0.05 . Furthermore, the confidence interval of $0.20-1.00$, although there is trend for benefit, still could be interpreted as having no difference from standard therapy. Further studies involving greater number of patients are warranted in order to minimize and to make the conclusions more robust.

Analysis of secondary outcomes showed a significant decrease in biomarkers. Since these biomarkers correlate to the degree of kidney injury even in the absence or delayed rise in serum creatinine, it could mean that it can protect the kidneys from renal injury attributed to contrast use that is not severe enough to impair glomerular filtration or an increase in serum creatinine. How this correlates to clinical outcomes such as decreased need for dialysis or decreased risk for cardiovascular events remains to be discovered.

\section{Limitations of the study}

The meta-analysis has several limitations. First, only 3 randomized controlled trials were included. More trials are needed with larger samples sizes to increase the statistical power of the results. No long term data are available to tell us whether there are long term benefits or harm in using Cordyceps if used on a regular basis. Thus, further studies need to be done to clarify the preventive effects of Cordyceps. Second, our search was not exhaustive enough to include articles of other languages. Perhaps inclusion of studies from other languages, particularly Chinese could have resulted to more articles being analyzed.

\section{CONCLUSION}

With the current data, there is not enough power to safely conclude whether Cordyceps has or has no benefit for the prevention of contrast-induced nephropathy. What we can conclude as of this moment, is that Cordyceps may have some benefit for the prevention of contrast-induced nephropathy among patients undergoing cardiac procedure using intravenous contrast and that early kidney injury might be alleviated by Cordyceps use as evidenced by the reduced concentration of novel biomarkers for kidney injury.

\section{Statement of Authorship}

All authors have approved the final version submitted.

\section{Author Disclosure}

All the authors declared no conflicts of interest.

\section{Funding Source}

This paper was partially funded by the Philippine General Hospital and the authors.

\section{REFERENCES}

1. Kidney Disease: Improving Global Outcomes (KDIGO) Acute Kidney Injury Work Group. KDIGO Clinical Practice Guideline for Acute Kidney Injury. Kidney inter., Suppl. 2012; 2:69-88.

2. Nash K, Hafeez A, Hou S. Hospital-acquired renal insufficiency. Am J Kidney Dis. 2002; 39(5):930-6.

3. Marenzi G, Lauri G, Assanelli E, et al. Contrast-induced nephropathy in patients undergoing primary angioplasty for acute myocardial infarction. J Am Coll Cardiol. 2004; 44(9):1780-5.

4. Rihal CS, Textor SC, Grill DE, et al. Incidence and prognostic importance of acute renal failure after percutaneous coronary intervention. Circulation. 2002; 105(19):2259-64.

5. McCullough PA, Wolyn R, Rocher LL, Levin RN, O'Neill WW. Acute Renal Failure after Coronary Intervention: Incidence, Risk Factors, and Relationship to Mortality. Am J Med. 1997; 103(5):368-75.

6. Balemans CE, Reichert LJ, van Schelven BI, van den Brand JA, Wetzels JF. Epidemiology of contrast material-induced nephropathy in the era of hydration. Radiology. 2012; 263(3):706-13.

7. Giacoppo D, Madhavan M, Baber U, et al. Impact of contrast-induced acute kidney injury after percutaneous coronary intervention on shortand long-term outcomes pooled analysis from the HORIZONS-AMI and ACUITY Trials. Circ Cardiovasc Interv. 2015; 8(8):e002475.

8. Parrikh CR, Mishra J, Thiessen-Philbrook H, et al. Urinary IL-18 is an early predictive biomarker of acute kidney injury after cardiac surgery. Kidney Int. 2006; 70(1):199-203.

9. $\mathrm{He} \mathrm{H}, \mathrm{Li} \mathrm{W}$, Qian W, et al. Urinary interleukin 18 as an early indicator to predict contrast-induced nephropathy in patients undergoing percutaneous coronary intervention. Exp Ther Med. 2014; 8(4):1263-6.

10. Mawad H, Laurin LP, Naud JF, et al. Changes in urinary and serum levels of novel biomarkers after administration of Gadolinium-based contrast agents. Biomark Insights. 2016; 11:91-4.

11. Brigouri C, Visconti G, Rivera NV, et al. Cystatin-C and contrastinduced acute kidney injury. Circulation. 2010; 121(19):2117-22.

12. Mishra J, Dent C, Tarabishi R, et al. Neutrophil gelatinase-associated lipocalin (NGAL) as a biomarker for acute renal injury after cardiac surgery. Lancet. 2005; 365(9466):1231-8.

13. Kafkas N, Liakos C, Zoubouloglou F, Dagadaki O, Dragasis S, Makris K. Neutrophil Gelatinase-Associated Lipocalin as an early marker of contrast-induced nephropathy after elective invasive cardiac procedures. Clin Cardiol. 2016; 39(8):464-70.

14. Tong J, Li H, Zhang $\mathrm{H}$, et al. Neutrophil Gelatinase-associated Lipocalin in the prediction of contrast-induced nephropathy: a systemic review and meta-analysis. J Cardiovasc Pharamacol. 2015; 66(3):239-45.

15. Khatami MR, Sabbagh MRP, Nikravan N, et al. The role of Neutrophil-Gelatinase Associated Lipocalin in early diagnosis of contrast nephropathy. Indian J Nephrol. 2015; 25(5):292-6.

16. Bonventre JV. Kidney injury molecule-1 (KIM-1): a urinary biomarker and much more. Nephrol Dial Transplant. 2009 24(11):3265-8.

17. Vijayasimha M, PadmaVV, Mujumdar SKD, Satyanarayana PVV, Yadav A. Kidney injury molecule-1: A urinary biomarker for contrastinduced acute kidney injury. Medical Journal of Dr. D.Y. Patil Vidyapeeth. 2014; 7(3):321-5.

18. Xie Y,Wang Q, Wang C, Qi C, Ni Z, Mou S. High urinary excretion of kidney injury molecule-1 predicts adverse outcomes in acute kidney injury: a case control study. Crit Care. 2016; 20(1):286.

19. Ren L, Ji J, Fang Y, et al. Assessment of urinary N-acetyl- $\beta$ glucosaminidase as an early marker of contrast-induced nephropathy. J Int Med Res. 2011; 39(2):647-53.

20. Chew SL, Lins RL, Daelemans R, Nuyts GD, De Broe ME. Urinary enzymes in acute renal failure. Nephrol Dial Transplant. 1993; 8:507-11.

21. European Society of Urogenital Radiology [Online]. 2008 [cited 2016 Oct]. Available from http://www.esur.org/ESUR_Guidelines.8.0.html.

22. Jurado-Román A, Hernández-Hernández F, García-Tejada J, et al. Role of hydration in contrast-induced nephropathy in patients who underwent primary percutaneous coronary intervention. Am J Cardiol. 2015; 115(9):1174-8. 
23. Azzalini L, Spagnoli V, Ly HQ. Contrast-induced nephropathy: from pathophysiology to preventive strategies. Can J Cardiol. 2016; 32(2):247-55.

24. Han Y, Zhu G, Han L, et al.Short-term rosuvastatin therapy for prevention of contrast-induced acute kidney injury in patients with diabetes and chronic kidney disease.J Am Coll Cardiol.2014;63(1):62-70.

25. Ji NF, Yao LS, Li Y, He W, Yi KS, Huang M. Polysaccharide of Cordyceps sinensis enhances cisplatin cytotoxicity in non-small cell lung cancer H157 cell line. Integr Cancer Ther. 2011; 10(4):359-67.

26. Hu T, Jiang C, Huang Q, Sun F. A comb-like branched $\beta$-d-glucan produced by a Cordyceps sinensis fungus and its protective effect against cyclophosphamide-induced immunosuppression in mice. Carbohydr Polym. 2016; 142:259-67.

27. Shao LW, Huang LH, Yan S, Jin JD, Ren SY. Cordycepin induces apoptosis in human liver cancer HepG2 cells through extrinsic and intrinsic signaling pathways. Oncol Lett. 2016; 12(2):995-1000.

28. Choi S, Lim MH, Kim KM, Jeon BH, Song WO, Kim TW. Cordycepin-induced apoptosis and autophagy in breast cancer cells are independent. Toxicol Appl Pharmacol. 2011; 257(2):165-73.

29. Zhou X,Lou L,Dressel W,et al.Cordycepin is an immunoregulatory active ingredient of Cordyceps sinensis. Am J Chin Med. 2008; 36(5):967-80.

30. Wang Y, Wang Y, Liu D, et al. Cordyceps sinensis polysaccharide inhibits PDGF-BB-inducedinflammation and ROS production in human mesangial cells. Carbohydr Polym. 2015; 125:135-45.

31. Liu H, Cao D, Liu H, Liu X, Mai W, Lan H, Huo W, Zheng Q. The herbal medicine Cordyceps sinensis protects pancreatic beta cells from streptozotocin-induced endoplasmic reticulum stress. Can J Diabetes. 2016; 40(4):1-7.

32. Cheng YJ, Cheng SM, Teng YH, Shyu WC, Chen HL, Lee SD. Cordyceps sinensis prevents apoptosis in mouse liver with D-Galactosamine/Lipopolysaccharide-induced fulminant hepatic failure. Am J Chin Med. 2014; 42(2):427-41.

33. Chen M, Cheung FW, Chan MH, et al. Protective roles of Cordyceps on lung fibrosis in cellular and rat models. J Ethnopharmacol. 2012; 143(2):448-54

34. Peng Y, Chen Q, Yang T, Tao Y, Lu X, Liu C. Cultured mycelium Cordyceps sinensis protects liver sinusoidal endothelial cells in acute liver injured mice. Mol Biol Rep. 2014; 41(3):1815-27.

35. Wu R, Gao JP, Wang HL, Gao Y,Wu Q, Cui XH. Effects of fermented Cordyceps sinensis on oxidative stress in doxorubicin treated rats. Phcog Mag. 2015; 11(44):724-31.

36. Luo Y, Yang Sk, Zhou X, et al. Use of Ophiocordyceps sinensis (syn. Cordyceps sinensis) combined with angiotensin-converting enzyme inhibitors (ACEI)/angiotensin receptor blockers (ARB) versus ACEI/ $\mathrm{ARB}$ alone in the treatment of diabetic kidney disease: a meta-analysis. Ren Fail. 2015; 37(4):614-34.

37. Zhang Z, Wang X, Zhang Y, Ye G. Effect of Cordyceps sinensis on renal function of patients with chronic allograft nephropathy. Urol Int. 2011; 86(3):298-301.

38. Liu X, Zhong F, Tang XL, et al. Cordyceps sinensis protects against liver and heart injuries in a rat model of chronic kidney disease: a metabolomic analysis. Acta Pharmacol Sin. 2014; 35(5):697-706.

The-Acta-Medica Philippina is now accepting original scientific papers, review articles and case reports for its upcoming issues. Please follow the format for submission as indicated in the "Instructions to Authors" elsewhere in the journal. All papers received shall be properly acknowledged. For inquiries and submission of proposals, please e-mail us at

Volume 52 editor@actamedicaphilippina.org

Number 12018

ISSN 0001-6071 


\section{APPENDICES}

Appendix A. Data extraction form

\begin{tabular}{|l|l|l|}
\hline Trial ID & Extractor & Year of publication \\
\hline Title & & \\
\hline Authors & \\
\hline Citation & \\
\hline
\end{tabular}

Participants

Inclusion criteria

Exclusion criteria

Intervention

Experiment group

Control/comparison group

Method

Quality assessment/ Risk of Bias Table

\begin{tabular}{|l|l|l|}
\hline \multicolumn{1}{|c|}{ Domain } & $\begin{array}{c}\text { Judgement } \\
\text { Low risk/ High risk/ Unclear }\end{array}$ & $\begin{array}{c}\text { Support for Judgement/ } \\
\text { Description }\end{array}$ \\
\hline Method of random sequence generation (Selection bias) & & \\
\hline Method of allocation concealment (Selection bias) & & \\
\hline Incomplete outcome data/ loss of participants to follow-up (Attrition bias) & & \\
\hline Blinding of participants and personnel (Performance bias) & & \\
\hline Blinding of outcome assessment (Detection bias) & & \\
\hline Selective reporting/ Intention to treat analysis (Reporting bias) & & \\
\hline Other bias & & \\
\hline
\end{tabular}

\section{Outcomes}

\begin{tabular}{|c|c|c|c|c|c|}
\hline & \multirow{3}{*}{ Outcome Measures } & \multicolumn{4}{|c|}{ Total= } \\
\hline & & \multicolumn{2}{|c|}{ Intervention group $\mathrm{N}=$} & \multicolumn{2}{|c|}{ Control group $\mathrm{N}=$} \\
\hline & & Events & Total & Events & Total \\
\hline & Primary: & & & & \\
\hline \multicolumn{6}{|l|}{1} \\
\hline & Secondary: & & & & \\
\hline \multicolumn{6}{|l|}{2} \\
\hline 3 & & & & & \\
\hline
\end{tabular}


Appendix B. Completed forms

\begin{tabular}{|l|l|l|}
\hline Trial ID 24024319 & Extractor: Marvyn Chan & Year of publication 2013 \\
\hline Title: Role of Dongchongxiacao (Cordyceps) in prevention of contrast-induced nephropathy in patients with stable angina pectoris \\
\hline Autho
\end{tabular}

Authors: Kai Zhao, Yongjian Li, Hong Zhang

Citation: J Tradit Chin Med 2013 June 15; 33(3): 283-286

Participants

\begin{tabular}{|c|c|}
\hline Inclusion criteria & $\begin{array}{l}\text { - }>18 \text { years and }<80 \text { years of age } \\
\text { - SAP had to conform to guidelines set by the relevant organization in China in } 2007\end{array}$ \\
\hline Exclusion criteria & $\begin{array}{l}\text { - hyperpyrexic or allergic to iodine } \\
\text { - who had: tumors; severe heart failure; severe liver or kidney failure; disorders of the immune system; blood diseases. }\end{array}$ \\
\hline
\end{tabular}

Intervention

\begin{tabular}{|l|l|}
\hline Experiment group & $\begin{array}{l}\text { Patients in the DCXC group received corbrin capsules capsules (Hangzhou Zhongmei Huadong Pharmaceuticals, } \\
\text { Hangzhou, China; 3 g; p.o.; t.d.s.) for 3 days before and after angioplasty. }\end{array}$ \\
\hline $\begin{array}{l}\text { Control/ } \\
\text { comparison group }\end{array}$ & $\begin{array}{l}\text { Subjects in the basic treatment group received hydration, } \\
\text { anti-platelet agents, statins, and anticoagulant therapy. }\end{array}$ \\
\hline
\end{tabular}

Method

All procedures were undertaken with low-osmolarity non-ionic contrast media (iopamidol, i.v.). The volume of contrast media used was recorded for all patients during catheterization.

Serum creatinine ( $\mathrm{Scr}$ ) was assessed at the time of hospital admission and 1, 2, and 3 days after the procedure. Values of kidney injury molecule-1 (KIM-1), neutrophil gelatinase-associated lipocalin (NGAL) and interleukin (IL) 18 in urine were recorded before and 1 day after the procedure in patients of both groups.

Quality assessment/ Risk of Bias Table

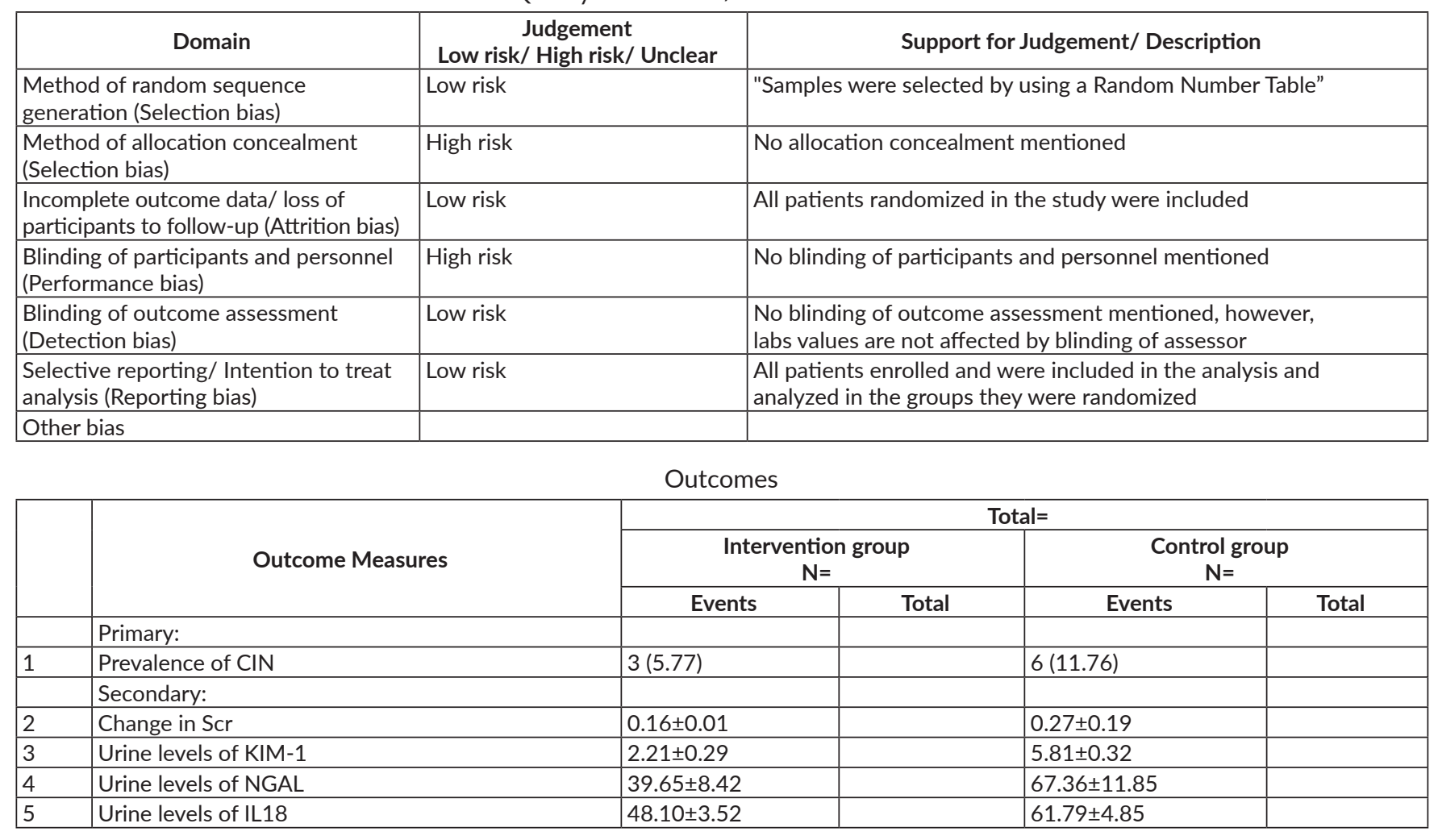




\begin{tabular}{|l|l|l|}
\hline Trial ID 25664103 & Extractor Kenneth Lim & Year of publication 2014 \\
\hline $\begin{array}{l}\text { Title: Efficacy of short-term cordyceps sinensis for prevention of contrast-induced nephropathy in patients with acute coronary syndrome } \\
\text { undergoing elective percutaneous coronary intervention }\end{array}$ \\
\hline Authors: Kai Zhao*, Yu Lin*, Yong-Jian Li, Sheng Gao \\
\hline Citation: Int J Clin Exp Med 2014;7(12):5758-5764 \\
\hline
\end{tabular}

Citation: Int J Clin Exp Med 2014;7(12):5758-5764

Participants

\begin{tabular}{|c|c|}
\hline Inclusion criteria & $\begin{array}{l}\text { - }>18 \text { years and }<75 \text { years of age } \\
\text { - ACS: diagnosed according to the criteria issued by American Heart Association, which includes acute myocardial } \\
\text { infarction and unstable angina pectoris. unstable angina pectoris and myocardial infarction attacked more than } 7 \text { days }\end{array}$ \\
\hline Exclusion criteria & $\begin{array}{l}\text { - Cardiac shock or state supported by device, such as intra-aortic balloon pump (IABP). } \\
\text { - hyperpyrexic or allergic to iodine or } \\
\text { - who had one of the following: severe kidney failure, severe congestive heart failure, severe liver failure, disorders of } \\
\text { the immune system, tumors, and blood diseases. }\end{array}$ \\
\hline
\end{tabular}

Intervention

\begin{tabular}{|l|l|}
\hline Experiment group & $\begin{array}{l}\text { Standard CS therapy group were given corbrin capsule 2 g, } 3 \text { times/d were used } 3 \text { days before and after PCl } \\
\text { Intensive CS therapy group were given corbrin capsule 3 g, 3 times/d were used 3 days before and after PCl }\end{array}$ \\
\hline $\begin{array}{l}\text { Control/ } \\
\text { comparison group }\end{array}$ & $\begin{array}{l}\text { All patients were hydrated with intravenous half-isotonic saline at a rate of } 1 \mathrm{mg} / \mathrm{kg} \text { per hour for } 12 \text { hours before and } \\
12 \text { hours after coronary catheterization } \\
\text { The decision to use aspirin, clopidogrel, beta-blockers, low-molecular-weight heparin preparations, angiotensin } \\
\text { converting enzyme inhibitors or angiotensin-II receptor antagonists, and statins was left to the discretion of } \\
\text { interventional and ward cardiologists, as directed by international guidelines. } \\
\text { Interventional procedure was performed according to standard clinical practice using the femoral or radial approach }\end{array}$ \\
\hline
\end{tabular}

Method

All patients were hydrated with intravenous half-isotonic saline at a rate of $1 \mathrm{mg} / \mathrm{kg}$ per hour for 12 hours before and 12 hours after coronary catheterization.

Decision to use aspirin, clopidogrel, beta-blockers, low-molecular-weight heparin preparations, angiotensin converting enzyme inhibitors or angiotensin-II receptor antagonists, and statins was left to the discretion of interventional and ward cardiologists, as directed by international guidelines.

All procedures were performed with the use of iso-osmolar nonionic contrast media iodixanol (Visipaque, $320 \mathrm{mg}$ iodine/mL, GE Healthcare, Shanghai, Co., Ltd.). Volume of contrast media was recorded for all patients during catheterization.

Serum creatinine (Scr) and estimated glomerular filtration rate (eGFR) were assessed at the time of hospital admission and 1,2, and 3 days after PCI. Values of kidney injury molecule-1 (KIM-1), interleukin (IL) 18 and neutrophil gelatinase-associated lipocalin (NGAL) in urine were recorded before and one day after PCI in patients of three groups. The eGFR was calculated by using the Modification of Diet in Renal Disease (MDRD) equation.

Quality assessment/ Risk of Bias Table

\begin{tabular}{|l|l|l|}
\hline \multicolumn{1}{|c|}{ Domain } & \multicolumn{1}{c|}{$\begin{array}{c}\text { Judgement } \\
\text { Low risk/ High risk/ Unclear }\end{array}$} & \multicolumn{1}{c|}{ Support for Judgement/ Description } \\
\hline $\begin{array}{l}\text { Method of random sequence } \\
\text { generation (Selection bias) }\end{array}$ & Low risk & $\begin{array}{l}\text { "According to a random number table, 150 eligible patients with } \\
\text { ACS were divided randomly into 3 groups" }\end{array}$ \\
\hline $\begin{array}{l}\text { Method of allocation concealment } \\
\text { (Selection bias) }\end{array}$ & High risk & No allocation concealment mentioned \\
\hline $\begin{array}{l}\text { Incomplete outcome data/ loss of } \\
\text { participants to follow-up (Attrition bias) }\end{array}$ & Low risk & All patients randomized in the study were included \\
\hline $\begin{array}{l}\text { Blinding of participants and personnel } \\
\text { (Performance bias) }\end{array}$ & High risk & No blinding of participants and personnel mentioned \\
\hline $\begin{array}{l}\text { Blinding of outcome assessment } \\
\text { (Detection bias) }\end{array}$ & Low risk & $\begin{array}{l}\text { No blinding of outcome assessment mentioned, however, } \\
\text { labs values are not affected by blinding of assessor }\end{array}$ \\
\hline $\begin{array}{l}\text { Selective reporting/ Intention to treat } \\
\text { analysis (Reporting bias) }\end{array}$ & Low risk & $\begin{array}{l}\text { All patients enrolled and were included in the analysis and } \\
\text { analyzed in the groups they were randomized }\end{array}$ \\
\hline Other bias & & \\
\hline
\end{tabular}


Outcomes

\begin{tabular}{|c|c|c|c|c|c|}
\hline & \multirow{3}{*}{ Outcome Measures } & \multicolumn{4}{|c|}{ Total= } \\
\hline & & \multicolumn{2}{|c|}{$\begin{array}{c}\text { Intervention group } \\
\mathrm{N}=\end{array}$} & \multicolumn{2}{|c|}{$\begin{array}{c}\text { Control group } \\
\mathrm{N}=\end{array}$} \\
\hline & & Events & Total & Events & Tota \\
\hline & Primary: & & & & \\
\hline 1 & Incidence of $\mathrm{CIN}$ & $\begin{array}{l}4 \text { (8.16) (Std) } \\
3 \text { (6.0) (Int) }\end{array}$ & & $6(11.76)$ & \\
\hline & Secondary: & & & & \\
\hline 2 & $\begin{array}{l}25 \% \text { or greater reduction in the eGFR compared to } \\
\text { baseline, }\end{array}$ & \begin{tabular}{|l|}
$5(10.2)(\mathrm{Std})$ \\
$4(8.0)(\operatorname{lnt})$ \\
\end{tabular} & & $7(13.73)$ & \\
\hline 3 & Changes in urine KIM-1 & $\begin{array}{l}4.84 \pm 0.32(\mathrm{Std}) \\
2.77 \pm 0.33 \text { (Int) } \\
\end{array}$ & & $5.63 \pm 0.27$ & \\
\hline 4 & Changes in urine IL-18 & $\begin{array}{l}55.78 \pm 4.17(\text { Std) } \\
46.78 \pm 4.33(\operatorname{lnt}) \\
\end{array}$ & & $62.14 \pm 3.53$ & \\
\hline 5 & Changes in urine NGAL & $\begin{array}{l}57.13 \pm 9.67 \text { (Std) } \\
41.66 \pm 8.42 \text { (Int) }\end{array}$ & & $66.53 \pm 10.74$ & \\
\hline
\end{tabular}

Extractor: Kenneth Lim

Year of publication 2015

Title: Effect of Dongchongxiacao (Cordyceps) therapy on contrast-induced nephropathy in patients with type 2 diabetes and renal insufficiency undergoing coronary angiography

Authors: Zhao Kai, Li Yongjian, Gao Sheng, Lin Yu

Citation: J Tradit Chin Med 2015 August 15; 35(4): 422-427

Participants

\begin{tabular}{|c|c|}
\hline Inclusion criteria & $\begin{array}{l}\text { - Type } 2 \text { diabetes } \\
\text { - estimated glomerular filtration rate (eGFR) was } \leq 60 \mathrm{~mL} / \mathrm{min} / 1.73 \mathrm{~m}^{2} \\
\text { - }>18 \text { years and }<80 \text { years of age } \\
\text { Type } 2 \text { diabetes was defined as any of the following: } \\
\text { - Fasting plasma glucose level greater than } 7.0 \mathrm{mmol} / \mathrm{L} \text { or a random plasma glucose level of } 11.1 \mathrm{mmol} / \mathrm{L} \text { or greater. } \\
\text { - Repeated measurement of fasting or random plasma glucose levels on subsequent days was used to confirm the } \\
\text { diagnosis of diabetes }\end{array}$ \\
\hline Exclusion criteria & $\begin{array}{l}\text { Hyperpyrexic or allergic to iodine or who had one of the following: } \\
\text { - tumors; severe heart failure; severe kidney failure; severe liver failure; disorders of the immune system; blood disease }\end{array}$ \\
\hline
\end{tabular}

Intervention

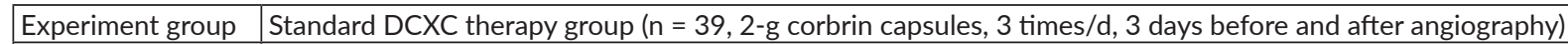

Control/ $\quad$ Intensive DCXC therapy group ( $n=40,3-\mathrm{g}$ corbrin capsules, 3 times/d, 3 days before and after angiography)

comparison group Basic treatment group $(n=41)$ - aspirin $(100 \mathrm{mg} / \mathrm{d}$ was administered indefinitely), clopidogrel (600 mg loading dose,

followed by $75 \mathrm{mg} / \mathrm{d}$ for at least $12 \mathrm{months})$, rosuvastatin $(10 \mathrm{mg} / \mathrm{d})$, metoprolol ( $23.75 \mathrm{mg} / \mathrm{d})$, benazepril (10 mg/d), fondaparinux ( $2.5 \mathrm{mg} / \mathrm{d}$ for at least 5 days), furosemide $(20 \mathrm{mg} / \mathrm{d}$ )

\section{Method}

All patients were given intravenous isotonic saline (0.9\%) at a rate of approximately $1 \mathrm{~mL} / \mathrm{kg}$ per hour for $6 \mathrm{~h}$ before, and $12 \mathrm{~h}$ after, contrast exposure.

All patients received aspirin (100 mg/d was administered indefinitely), clopidogrel (600 $\mathrm{mg}$ loading dose, followed by $75 \mathrm{mg} / \mathrm{d}$ for at least 12 months), rosuvastatin ( $10 \mathrm{mg} / \mathrm{d}$ ), metoprolol $(23.75 \mathrm{mg} / \mathrm{d})$, benazepril (10 mg/d), fondaparinux ( $2.5 \mathrm{mg} / \mathrm{d}$ for at least 5 days), furosemide $(20 \mathrm{mg} / \mathrm{d})$ Use of these medications were left to the discretion of the cardiologist according to clinical requirements or guideline recommendations.

All procedures were undertaken with low-osmolarity non-ionic contrast media (lopamidol, i.v.). The volume of contrast media used was recorded for all patients during catheterization. Serum levels of triglycerides (TG), total cholesterol (TC), high-density lipoprotein-cholesterol (HDL-C), low-density lipoprotein-cholesterol (LDL-C), blood glucose, and glycosylated hemoglobin, were measured at the time of hospital admission. Serum creatinine ( $\mathrm{Scr}$ ) and eGFR were measured at the time of hospital admission and 1, 2 and 3 days after the procedure. The concentration of urine neutrophil-gelatinase-associates-lipocalin (NGAL), kidney injury molecule-1 (KIM-1), and interleukin-18 (IL-18) in urine were detected before and one day after the procedure for patients in three groups. The urine levels of NGAL, IL-18 and KIM-1 were determined by enzyme-linked immunosorbent assay (ELISA) in the clinical laboratory of Tianjin Nankai Hospital. 
Quality assessment/ Risk of Bias Table

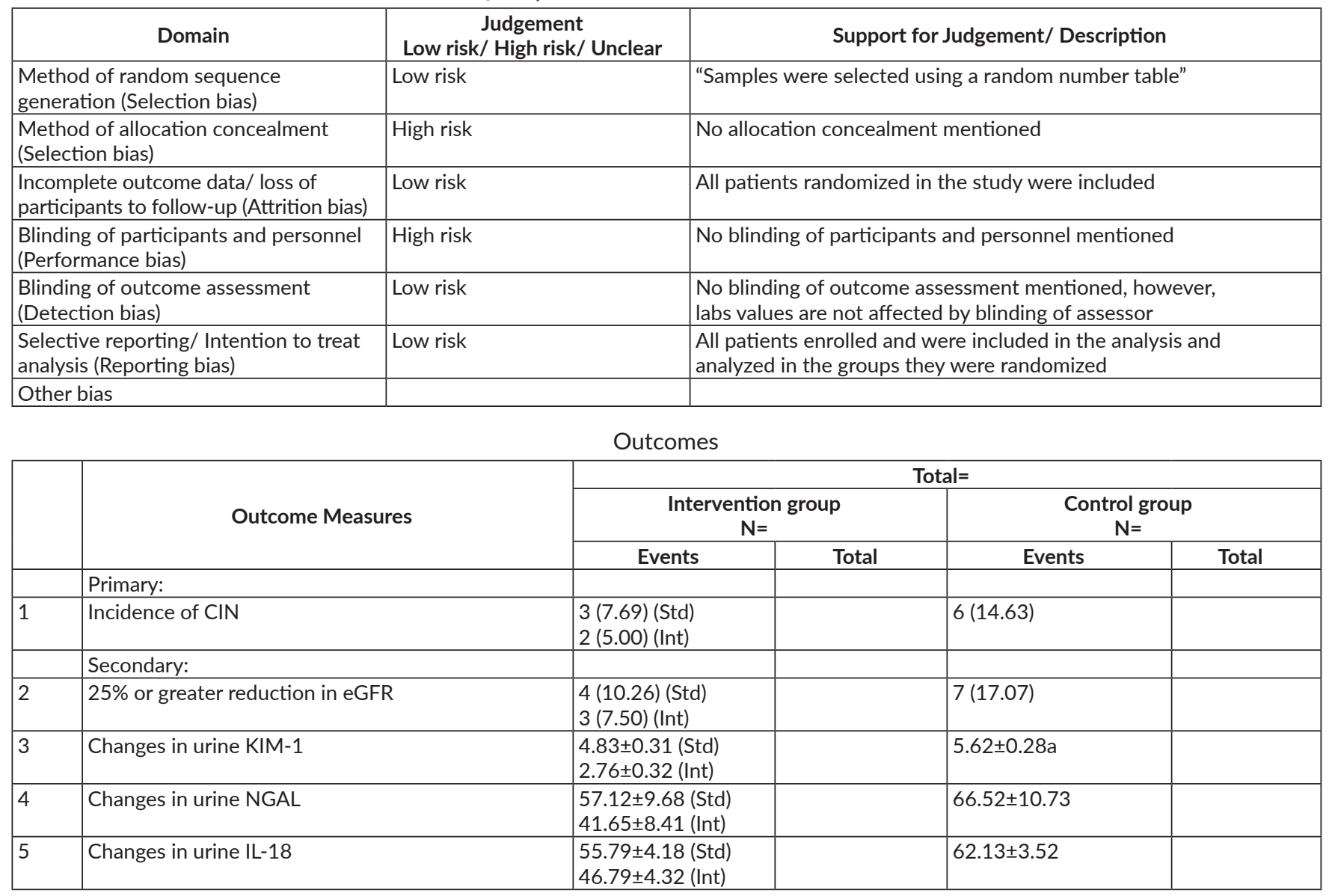

